\title{
Eventos de Vida Positivos e Negativos em Crianças
}

\author{
Claudia Hofheinz Giacomoni ${ }^{1}$ \\ Departamento de Psicologia do Desenvolvimento e da Personalidade da Universidade \\ Federal do Rio Grande do Sul, Porto Alegre, RS, Brasil \\ Luciana Karine de Souza \\ Programa de Pós-Graduação Interdisciplinar em Estudos do Lazer da Universidade \\ Federal de Minas Gerais, Belo Horizonte, MG, Brasil \\ Programa de Pós-Graduação em Psicologia da Universidade Federal do Rio Grande do Sul, \\ Porto Alegre, RS, Brasil \\ Claudio Simon Hutz \\ Departamento de Psicologia do Desenvolvimento e da Personalidade da Universidade \\ Federal do Rio Grande do Sul, Porto Alegre, RS, Brasil
}

\begin{abstract}
Resumo
Pesquisas sobre bem-estar subjetivo e satisfação de vida em crianças também investigam o autorrelato de eventos de vida. Este estudo buscou investigar quais eventos de vida, positivos e negativos, são mais frequentes na vida das crianças, na sua percepção, e realizar comparações por sexo, por tipo de escola e por faixa etária. Duzentas crianças (5 a 12 anos) foram individualmente entrevistadas, e as falas transcritas foram analisadas mediante análise de conteúdo. Os eventos de vida positivos mais citados foram família (destacados pelas meninas), lazer, amizade (mais citados pelas crianças de 11-12 anos), escola e ganhar presentes. Os eventos negativos mais mencionados foram morte (mais referida pelas meninas, e não citadas pelas crianças de 5-6 anos), desentendimento familiar, privação, saúde/doença e desentendimento com amigos (salientadas pelas crianças de 5-6 anos). Os resultados estão de acordo com a literatura internacional e nacional. Recomendações para a intervenção na escola e na clínica são traçadas.
\end{abstract}

Palavras-chave: Infância, bem-estar, eventos de vida, satisfação, felicidade.

\section{Positive and Negative Life Events in Children}

\begin{abstract}
Research on subjective well-being and life satisfaction in children also analyze self-reported life events. This study investigated which life events, positive and negative, are more frequent in the lives of Brazilian children, according to their own view. We also conducted gender, type of school, and age range comparisons. Two hundred children (5- to 12 years old) were individually interviewed, and their
\end{abstract}

Endereço para correspondência: Universidade Federal do Rio Grande do Sul, Instituto de Psicologia, Rua Ramiro Barcelos, 2600, sala 124, bairro Santa Cecília, Porto Alegre, RS, Brasil 90035-003. Fone/fax: (51) 3308-5338. E-mail: giacomonich@gmail.com

Agradecimentos: L. Stein, R. Arendt, A. Biaggio, D. Bandeira, D. Dell'Aglio, S. Blatt, A. Tibulo, G. Mazzini, J. Zanchetin, A. Silveira, C. Oliveira, C. Hartmann, D. D’Incão, I. Gemeli, L. Azevedo e Souza, M. Fischborn, R. Ebert, T. Schmidt, V. Nachtigall, Z. Silveira.

Apoio: Coordenação de Aperfeiçoamento de Pessoal de Nível Superior (CAPES); Programa de Pós-Graduação (PPG) em Psicologia da Universidade Federal do Rio Grande do Sul. 
answers were submitted to content analyzes. The most cited positive life events were family (mainly by girls), leisure, friendship (highlighted by 11-12 years-old children), school, and presents. The negative life events more frequently mentioned were death (mostly referred by girls, and not mentioned at all by 5-6 year-old's), family conflicts, privations (lack of money, lack of company as in staying home alone), health/diseases, and friendship conflicts (mainly cited by 5-6 year-old's). Results are similar to the international and national scientific literature. We present recommendations for clinical and educational interventions.

Keywords: Children, well-being, life events, satisfaction, happiness.

\section{Eventos de Vida Positivos y Negativos en Niños y Niñas}

\section{Resumen}

Las investigaciones sobre bienestar subjetivo y satisfacción de vida en la infancia, también analizan auto-reportes de eventos de vida. Este estudio tuvo como objetivo investigar los eventos de vida, positivos y negativos, más frecuentes en niños y niñas brasileños, en su percepción, y realizar comparaciones por sexo, escuela y edad. Doscientos niños (5-12 años) fueron entrevistados individualmente y la transcripción de las entrevistas fue analizada mediante análisis de contenido. Los eventos de vida positivos más citados fueron familia (destacado por las niñas), ocio, amistad (más citado por los participantes de 11-12 años), escuela y recibir regalos. Los eventos adversos más citados fueron la muerte (más citado por niñas, no siendo mencionado por participante de 5-6 años), desacuerdo familiar, privación, salud/ enfermedad y desacuerdo con los amigos (resaltado por niños y niñas de 5-6 años). Los resultados concuerdan con la literatura internacional y nacional. Algunas recomendaciones para la intervención en la escuela y la clínica son formuladas.

Palabras clave: Infancia, bienestar, eventos de vida, satisfacción, felicidad.

Na avaliação da qualidade de vida infantil, importam não somente indicadores objetivos, mas também dados subjetivos da experiência da criança sobre domínios de sua vida, seus afetos e eventos que julga marcarem sua história pessoal, positiva ou negativamente. De fato, no âmbito dos estudos sobre bem-estar subjetivo, também é investigado o impacto dos eventos de vida sobre a visão do próprio bem-estar (Suh, Diener, \& Fujita, 1996).

$\mathrm{Na}$ visão de Diener, Lucas, Oishi, e Suh (2002), bem-estar subjetivo (BES) consiste de três componentes correlacionados: satisfação de vida (avaliação cognitiva global da vida da pessoa), afeto positivo e ausência de afeto negativo. Afeto positivo ou negativo diz respeito à intensidade e frequência com as quais se experienciam emoções positivas ou negativas. O presente estudo não trata diretamente da questão do BES na infância, mas dos eventos de vida positivos e negativos em crianças. Há uma relação considerável entre eventos de vida e BES.

Em um estudo sobre a mensuração de eventos de vida (EV), Woyciekoski, Natividade, e Hutz (2014) perceberam que não há uma definição e um tratamento unívocos para a expressão. Ainda assim, resumindo-se as definições identificadas pelos autores, pode-se entender que EV são acontecimentos cotidianos, psicológicos ou físicos, que alteram ou que podem alterar a rotina da pessoa nos âmbitos pessoal ou social, podendo ser de maior ou menor importância para o sujeito e, ainda, positivos, negativos ou neutros. Ademais, Woyciekoski, Stenert, e Hutz (2012), em sua análise da literatura sobre a relação entre BES e EV, notaram que EV percebidos como positivos aumentam o BES e os negativos o diminuem.

Eventos negativos têm recebido maior atenção devido ao seu potencial ameaçador à qualidade de vida. No que se refere ao impacto dos 
EV sobre as pessoas, os pesquisadores têm pesquisado mais sobre como as pessoas lidam com o estresse causado por choques externos e suas consequências psicológicas (por exemplo, estudos sobre coping; Zeidner \& Endler, 1996). É o estudo dos eventos negativos, traumáticos e estressantes.

Um exemplo dessa tendência é o trabalho de Oliveira, Fonseca e Del Porto (2002) sobre a versão brasileira da entrevista de Paykel para EV recentes (últimos seis meses), com interesse especial na relação entre eventos estressantes e o desencadeamento de transtornos psiquiátricos em adultos. A versão brasileira agrupou 63 eventos nas categorias trabalho, educação, finanças, saúde, luto, migração, namoro/coabitação e família/relações sociais.

No caso dos EV positivos, aqueles identificados como mais relacionados às causas da felicidade (entendida como BES) são os relacionamentos com amigos, prazeres básicos da comida, da bebida e do sexo, e experiências de sucesso (Argyle, 1999). Dos tipos de eventos, os familiares são os mais citados. Entretanto, segundo o estudo de Larson (1990), as pessoas encontram-se em melhor humor na companhia de amigos, do que de familiares ou sozinhas. Além disso, a felicidade correlaciona-se positiva e significativamente com número de amigos, incluindo a frequência de encontro, ida a festas e danceterias, assim como a pertença a clubes sociais e esportivos. Quanto aos benefícios dos eventos positivos, estes remetem à satisfação de necessidades básicas, como sexo, comida, bebida, contato social e amigos (Larson, 1990).

Merece destaque o fato de que ainda são escassos os trabalhos sobre EV positivos (Albornoz \& Bandeira, 2010). Maybery, Jones-Ellis, Neale, e Arentz (2006) desenvolveram uma escala para avaliar a frequência e a intensidade de EV positivos em adultos. A validação da escala gerou oito componentes: relacionamento próximo com esposo/parceiro, diversão com os filhos, pais, amigos, chefe, colegas de trabalho, o trabalho em si, e eventos sociais.

De fato, no Brasil prevalecem estudos sobre EV estressantes, traumáticos ou negativos, especialmente em crianças e adolescentes. Tal é o estado da arte em pesquisa e clínica, que Albornoz e Bandeira (2010) o ilustram com uma busca bibliográfica de trabalhos científicos sobre EV em crianças e adolescentes, com foco na violência sexual. O levantamento conceitual das autoras identificou pontos em comum na definição de EV, descrita como "eventos que afetam" ou "mudam a vida das pessoas" (p. 490), dos quais os mais citados e estudados são os estressantes e negativos, especialmente a violência. Segundo Albornoz e Bandeira (2010), os EV sofrem influências sócio-histórico-culturais, genéticas, de condições de saúde/doença, fatores psicossociais, traumas e vulnerabilidades desenvolvimentais, estas especificamente nas fases da infância e adolescência.

No trabalho de King, Molina, e Chassin (2008) foram abordados EV negativos e incontroláveis do ponto de vista de adolescentes. Os eventos listados foram: problema sério com irmã(o)(s) (drogas, escola, etc.), doença ou problema sério com amigo próximo, problemas financeiros sérios dos pais, parentes falaram mal do(a) pai/mãe, pai/mãe brigaram com parentes, vizinhos falam mal do pai/mãe, pai/mãe agem mal na frente de seus amigos, pai/mãe foi preso(a), pai/mãe perdeu o emprego, trocou de escola porque a família se mudou, um amigo próximo se mudou para longe, pais se separaram, e ser vítima de um crime. Dos 13 eventos, nota-se que apenas quatro deles não envolvem os pais, o que sugere o impacto destes na vida do adolescente, em sua percepção.

Kristensen, Leon, D'Incao, e Dell'Aglio (2004) avaliaram eventos estressores em 330 adolescentes de 12 a 17 anos de idade, todos estudantes de escolas estaduais de Porto Alegre ou Novo Hamburgo (RS).

Os cinco eventos estressores mais frequentes foram ter provas no colégio (84\%), discutir com amigos(as) (79\%), morte de algum familiar (que não pais ou irmãos) (73\%), ter que obedecer às ordens de seus pais $(71 \%)$ e ter brigas com irmãos(ãs) (66\%) (p. 46).

Nos meninos "foram mais frequentes os eventos envolvendo problemas com a escola e com a polícia", violência, "dormir na rua", doenças e lesões, e "sofrer acidente". Nas meni- 
nas foram mais frequentes os seguintes eventos: dúvidas/"problemas quanto às mudanças no corpo"/aparência, "discutir com amigos(as)", mudança (colégio, casa ou cidade), morte de/brigas com irmãos(ãs), "ser impedido(a) de ir a festas"/ passeios, obedecer aos pais, "ter crises nervosas", e "não receber cuidado"/atenção dos pais (Kristensen et al., 2004, p. 46).

Poletto, Koller, e Dell'Aglio (2009) investigaram eventos estressores em 269 crianças e adolescentes em situação de vulnerabilidade social, 142 das quais viviam com familiares, e 155 estavam institucionalizadas. Os eventos mais frequentes foram, em ordem decrescente: ter de obedecer aos pais (85\%), discutir com amigos(as), rodar de ano na escola (repetir o ano escolar), ter brigas com irmãos(ãs), mudar de casa/cidade, mudar de colégio, família não ter dinheiro, sofrer castigos/punições, alguém da família perder o emprego, ter que viver em abrigo, separação dos pais, problemas com professores, ir para o conselho tutelar, e ter dificuldades em fazer amizades (32\%). Para as meninas, ter um familiar que "bebe muito", ter familiares doentes/deficientes, ter problemas/dúvidas sobre mudanças corporais ou aparência, morte de irmãos, e ser tocada sexualmente foram os eventos estressores que as diferenciaram significativamente dos meninos. Para estes últimos, sofrer acidente, ser expulso da sala pela professora, ser assaltado, e ser suspenso ou expulso da escola foram os eventos que se destacaram em suas falas, na comparação com as meninas.

Crianças espanholas foram abordadas por Thoilliez (2011) em uma pesquisa sobre felicidade (considerada pela autora como BES) em crianças e suas aplicações à educação. Dentre os tópicos estudados, o autor solicitou a 817 meninos e meninas, de 6 a 12 anos de idade, que citassem EV e situações cotidianas associadas à felicidade e à infelicidade. Os eventos encontrados a partir da fala das próprias crianças foram agrupados nos seguintes temas: família (33\%, que apresentou a maior porcentagem de eventos; boas e más experiências), amizade e relações de pares (aspectos positivos e rejeição social), desempenho escolar (bom e mau), festas e ocasiões especiais (aniversário, Natal e ganhar presentes, em sua maioria), tempo livre e obrigações (tensão entre ter tempo livre e cumprir com obrigações escolares), doenças e machucados, e moralidade e valores (ajudar, compartilhar, mentir, ser insultado). Embora a maioria agrupados, os eventos positivos e negativos abrangem temas em comum com as pesquisas sobre eventos negativos ou estressores, como os problemas na escola, conflitos familiares, desentendimentos com amigos, doenças e privações materiais.

Giacomoni (1998) investigou EV de 165 crianças (idade média de 9,5 anos) de escolas públicas de Porto Alegre. As crianças foram entrevistadas individualmente sobre eventos positivos e negativos. Os eventos positivos encontrados foram organizados nas seguintes categorias, em ordem decrescente de porcentagem de respostas: família $(21,3 \%)$, lazer, ganhar presentes, brincar, escola, esporte, datas festivas, amizade, outras respostas, situação econômica, relação com animais, e saúde. Os eventos negativos foram agrupados da seguinte forma: saúde (26,3\%), desentendimento familiar, inimizade, privação, outras respostas, morte, problemas na escola, medo, maus-tratos/morte de animais/ plantas, briga dos pais, e dificuldades econômicas. Os eventos listados no estudo de Giacomoni (1998), assim como no de Poletto et al. (2009), são menos específicos do que os listados por King et al. (2008), embora lidem com domínios similares, como amizade, família, saúde, recursos financeiros e necessidades materiais, e escola. Estes domínios mais amplos também são encontrados no trabalho de Thoilliez (2011).

Dell>Aglio (2000) investigou EV de 105 crianças institucionalizadas e 110 não institucionalizadas, todas de Porto Alegre, com idade média de 10 anos. Os eventos positivos de vida citados pelos participantes dos dois grupos foram: diversão, passeios/viagens, escola, família, amizade, ganhar/comprar coisas, institucionalização, mudança, aniversários/festas, e outras respostas. Os eventos negativos foram doença, morte, problemas na escola, problemas familiares, desentendimentos com pares, privação/ afastamento, impedimento/obrigação, receber castigos/ser xingado, violência, institucionalização, perigo, mudança, e outras respostas. Escola 
e passeios foram os mais frequentes nos participantes institucionalizados, enquanto que para as crianças residentes com suas famílias foram mais frequentes a família e, em segundo lugar, escola e diversão com a mesma porcentagem. Assim como os trabalhos de Giacomoni (1998) e de Thoilliez (2011), a pesquisa de Dell〉Aglio organizou as respostas das crianças e adolescentes em grupos temáticos mais amplos de respostas para eventos positivos e negativos, ao passo que no estudo de King et al. (2008), no qual constam apenas eventos negativos, os mesmos foram bastante especificados.

Em comum, as duas pesquisas brasileiras que examinaram eventos negativos bem como positivos (Dell〉Aglio, 2000; Giacomoni, 1998) citados por crianças e adolescentes indicam família, escola, amizade, ganhar presentes e ganhar/ comprar coisas, datas festivas e aniversários/festas, diversão e lazer/brincar como eventos positivos. Para eventos negativos, as duas pesquisas se assemelham em dados nos conteúdos como saúde/morte e doença/morte, desentendimento familiar e problemas familiares, problemas na escola, inimizade e desentendimentos com pares, privação e privação/afastamento, medo e perigo. Estes dados sugerem categorias de respostas para estudos subsequentes.

Muitos dos estudos brasileiros obtidos na revisão da literatura sobre $\mathrm{EV}$ em crianças e adolescentes utilizam, na coleta de dados, instrumentos estruturados para avaliar eventos positivos e negativos, sua frequência e intensidade ou impacto. Foram esses os casos das pesquisas relatadas por Kristensen et al. (2004), Oliveira et al. (2002), e Poletto et al. (2009), os dois últimos com o mesmo instrumento (Inventário de Eventos Estressores na Infância/Adolescência). Dois estudos (Dell>Aglio, 2000; Giacomoni, 1998) apresentaram questões abertas às crianças sobre eventos positivos e negativos de suas vidas. Excetuando-se o trabalho de Dell〉Aglio (2000) que se interessou por comparar os eventos de crianças institucionalizadas com crianças que moravam com familiares, resta apenas o trabalho de Giacomoni (1998) com crianças, a princípio, sem indicadores de risco social mais explícito.
Nesse sentido, a pesquisa sobre EV em crianças e adolescentes típicos no Brasil ainda carece de mais investigações especialmente de caráter mais indutivo por meio de consulta às próprias crianças sobre acontecimentos bons e ruins de suas vidas. Identificar esses eventos com base na perspectiva da própria criança é não apenas dar oportunidade para que ela se posicione sobre suas próprias experiências, evitando terceirizá-las através da fala de pais, professores e profissionais da saúde, mas também fortalecer metodologicamente a investigação científica no tema. $\mathrm{O}$ desenvolvimento de instrumentos mais objetivos de mensuração desses eventos positivos e negativos, bem como sua frequência, intensidade/impacto e relação com outros aspectos da felicidade (como a satisfação geral de vida e os afetos positivos e negativos) são considerados passos subsequentes na área.

Este trabalho buscou investigar quais eventos de vida, positivos e negativos, são mais frequentes na vida das crianças, na sua percepção, e realizar comparações por sexo, por tipo de escola e por faixa etária. A expectativa é de que os eventos identificados contribuam para a elaboração de instrumentos para avaliação do bem-estar na infância.

\section{Método}

\section{Participantes}

O estudo contou com 200 crianças na amostra, com idades de 5 a 12 anos. Durante a coleta de dados todas estudavam em escolas públicas ou privadas da cidade de Porto Alegre (Rio Grande do Sul). A amostra foi obtida por conveniência.

\section{Instrumentos}

Duas perguntas foram apresentadas às crianças para este estudo sobre eventos de vida positivos e negativos na infância: "O que aconteceu de bom da tua vida?" e "O que aconteceu de ruim na tua vida?". Ambas as questões buscam a definição de EV obtida na literatura, formuladas em linguagem de fácil compreensão pelas crianças mais novas da amostra. Cada criança poderia mencionar quantos $\mathrm{EV}$ quisesse. 


\section{Procedimentos}

Os pais/responsáveis pelas crianças permitiram sua participação, e as crianças que aceitaram de vontade própria, após a permissão dos pais, compuseram a amostra. As crianças foram entrevistadas individualmente em local apropriado nas dependências da escola onde estudavam, com autorização da instituição, tendo privacidade e sigilo garantidos. As entrevistas foram gravadas e transcritas para posterior análise. As escolas participantes já haviam contribuído com pesquisas anteriores e, por conveniência, foram contatadas para colaborar novamente. O estudo foi aprovado pelo Comitê de Ética da Universidade.

\section{Análise dos Dados}

As transcrições das respostas das crianças tiveram seu conteúdo analisado por dois avaliadores independentes, considerando seu significado semântico com critérios de análise sugeridos por Bardin (2011). Assim, na primeira etapa da análise realizou-se a leitura completa de todas as transcrições, para fins de familiarização com os dados e uma visão geral das respostas às duas questões e primeiras intuições sobre agrupamentos semânticos. Na segunda etapa da análise foram efetivamente empreendidos agrupamentos de respostas semelhantes em conteúdo, ou seja, com sentido similar. Na terceira e última etapa, os agrupamentos foram revisados, as dúvidas foram discutidas com a pesquisadora-responsável e dirimidas. Em seguida, categorias de respostas foram criadas por questão, ou seja, categorias para EV positivos e para EV negativos. Para a definição das categorias utilizou-se como diretrizes gerais a proximidade temática e indicativos da literatura.

Construídas as categorias de respostas por questão, foram calculadas frequências e porcentagens de respostas por categoria. Foram realizadas comparações por sexo e por tipo de escola com base no teste binomial de diferenças entre duas proporções (Hinkle, Wiersma, \& Jurs, 1988), e comparações através do teste do qui-quadrado para várias proporções (Ayres, Ayres, Ayres, \& Santos, 2000) para analisar diferenças nas faixas de idade de 5-6 anos, 7-8 anos, 9-10 anos e 11-12 anos. As faixas etárias foram estabelecidas com base em estudo anterior (Giacomoni \& Hutz, 2008). O nível de significância observado nos testes foi de 0,05.

\section{Resultados}

Foram extraídas 10 categorias referentes aos EV positivos e 8 categorias referentes aos EV negativos. Observou-se um total de 376 eventos positivos e 271 eventos negativos.

\section{Eventos de Vida Positivos}

Os EV positivos foram unidos nas seguintes categorias:

- Família: inclui boa convivência com a família (passear com os pais), a reconciliação dos pais, o rever um dos pais, visitar parentes (avós, primos, tios), o nascimento de algum parente (principalmente irmãos), dar presente para os pais, ir ao trabalho dos pais.

- Lazer: atividades divertidas, brincar, passear, sair, viajar, brinquedos, brincadeiras infantis coletivas, desenhar, pintar, praticar esportes, educação física na escola, competições, campeonatos. Exemplos: brincar de Barbie; jogar botão; jogar videogame; assistir à televisão; dançar; ir a parques abertos ou parques de diversão; tomar banho de piscina, açude ou rio; ir a estádios de futebol; ir ao cinema; viajar para a praia; ir ao shopping; andar de skate, roller, bicicleta.

- Amizade: convivência com amigos, fazer amigos, brincar com amigos, visitar amigos.

- Escola: variados eventos relacionados à vida escolar, como a entrada na escola, aprender a ler e escrever, aprendizagem, bom desempenho, estudar, "passar de ano", fazer os "temas de casa" (lição de casa), ter bom relacionamento com professora e/ou colegas.

- Ganhar presentes: ganhar presentes, brinquedos, roupas e doces.

- Melhor situação financeira e condição de vida (nas tabelas, constará "melhores finanças"): melhor padrão de vida financeiro, como um dos pais ter arranjado um emprego e/ou a aquisição de algum bem, como casa própria. 
- Comemoração de datas festivas/comemorativas: o próprio aniversário ou de outrem, feriados comemorativos, Natal, Páscoa, Dia das Mães ou dos Pais.

- Saúde: preocupação com o bem-estar físico próprio, de familiares e/ou amigos, no sentido de melhora ou de possuir saúde, cura, prevenção, ausência de doença. Exemplos: "minha mãe melhorou", "tomei vacina", "meu pai saiu do hospital".

- Outras respostas: respostas que não puderam ser incluídas nas categorias.

- Nada/não sabe.
As frequências e porcentagens das categorias de eventos positivos são apresentados na Tabela 1, por sexo, bem como o resultado do teste binomial para diferenças entre proporções. Não constam na tabela os resultados para outras respostas $(n=23 ; f=28 ; 7,5 \%)$ e para nada/não sei $(n=7 ; f=7 ; 1,9 \%)$. Os testes de diferenças entre proporções apontaram diferenças significativas entre os sexos na categoria "família", mais citada pelas meninas $(p=0,01)$, e na categoria "comemoração de datas festivas", mais frequente entre meninos $(p=0,04)$.

Tabela 1

Frequências, Porcentagens e Resultados do Teste Binomial para Diferenças entre Duas Proporções nos Eventos de Vida Positivos, por Sexo

\begin{tabular}{|c|c|c|c|c|c|c|c|c|}
\hline & \multicolumn{2}{|c|}{ Total } & \multicolumn{2}{|c|}{ Meninas } & \multicolumn{2}{|c|}{ Meninos } & \multirow[b]{2}{*}{$Z$} & \multirow[b]{2}{*}{$p$} \\
\hline & $n$ & $f(\%)$ & $n$ & $f(\%)$ & $n$ & $f(\%)$ & & \\
\hline Família & 84 & $113(30)$ & 50 & $69(36)$ & 34 & $44(24)$ & 2,40 & 0,01 \\
\hline Lazer & 62 & $79(21)$ & 31 & $40(21)$ & 31 & $39(21)$ & $-0,19$ & 0,84 \\
\hline Amizade & 31 & $35(9)$ & 17 & $19(10)$ & 14 & $16(9)$ & 0,33 & 0,73 \\
\hline Escola & 31 & $34(9)$ & 14 & $15(8)$ & 17 & $19(10)$ & $-0,91$ & 0,36 \\
\hline Ganhar presentes & 30 & $34(9)$ & 13 & $13(7)$ & 17 & $21(11,5)$ & $-1,63$ & 0,10 \\
\hline Melhores finanças & 15 & $18(5)$ & 7 & $9(5)$ & 8 & $9(5)$ & $-0,13$ & 0,88 \\
\hline Datas festivas & 13 & $15(4)$ & 4 & $4(2)$ & 9 & $11(6)$ & $-1,97$ & 0,04 \\
\hline Saúde & 12 & $13(3,5)$ & 9 & $10(5)$ & 3 & $3(2)$ & 1,85 & 0,06 \\
\hline
\end{tabular}

Nota. $p<0,05$.

A Tabela 2 mostra as frequências e porcentagens das categorias de eventos positivos, por tipo de escola, bem como o resultado do teste binomial para diferenças entre proporções. Não foram encontradas diferenças significativas entre tipos de escola.

Na Tabela 3 constam os resultados por faixa etária, com frequências, porcentagens e o teste do qui-quadrado das categorias de eventos de vida positivos. Verificaram-se diferenças significativas entre as faixas de idade para a questão da amizade e das datas festivas. Ainda que o teste não especifique, é interessante notar que as crianças de 7-8 anos foram as que menos mencionaram os amigos, e as de 11-12 anos as que mais mencionaram. Nas datas festivas, é digno de nota que as crianças menores da amostra citaram pouco este conteúdo em suas respostas, na comparação com as outras faixas de idade. 
Tabela 2

Frequências, Porcentagens e Resultados do Teste Binomial para Diferenças entre Duas Proporções nos Eventos de Vida Positivos, por Tipo de Escola

\begin{tabular}{|c|c|c|c|c|c|c|}
\hline & \multicolumn{2}{|c|}{ Pública } & \multicolumn{2}{|c|}{ Privada } & \multirow[b]{2}{*}{$Z$} & \multirow[b]{2}{*}{$p$} \\
\hline & $n$ & $f(\%)$ & $n$ & $f(\%)$ & & \\
\hline Família & 28 & $38(38)$ & 17 & $26(26,5)$ & 1,77 & 0,07 \\
\hline Lazer & 8 & $11(11)$ & 14 & $16(16)$ & $-1,06$ & 0,28 \\
\hline Amizade & 7 & $8(8)$ & 14 & $15(15)$ & $-1,57$ & 0,11 \\
\hline Escola & 9 & $10(10)$ & 10 & $12(12)$ & $-0,47$ & 0,63 \\
\hline Ganhar presentes & 8 & $9(9)$ & 4 & $5(5)$ & 1,08 & 0,27 \\
\hline Melhores finanças & 7 & $8(8)$ & 4 & $6(6)$ & 0,53 & 0,59 \\
\hline Datas festivas & 1 & $1(1)$ & 3 & $3(3)$ & $-1,02$ & 0,30 \\
\hline Saúde & 4 & $4(4)$ & 5 & $6(6)$ & $-0,66$ & 0,50 \\
\hline
\end{tabular}

Nota. $p<0,05$.

Tabela 3

Frequências, Porcentagens e Resultados do Teste do Qui-Quadrado das Categorias de Eventos de Vida Positivos, por Faixa Etária

\begin{tabular}{|c|c|c|c|c|c|c|c|c|c|c|}
\hline & \multicolumn{2}{|c|}{ 5-6 anos } & \multicolumn{2}{|c|}{$7-8$ anos } & \multicolumn{2}{|c|}{$9-10$ anos } & \multicolumn{2}{|c|}{ 11-12 anos } & \multirow[b]{2}{*}{$X^{2}$} & \multirow[b]{2}{*}{$p$} \\
\hline & $n$ & $f(\%)$ & $n$ & $f(\%)$ & $n$ & $f(\%)$ & $n$ & $f(\%)$ & & \\
\hline Família & 7 & $9(16)$ & 25 & $30(34)$ & 30 & $42(34)$ & 20 & $30(29)$ & 6,41 & 0,09 \\
\hline Lazer & 15 & $17(31)$ & 15 & $22(25)$ & 15 & $22(18)$ & 15 & $16(15)$ & 6,81 & 0,07 \\
\hline Amizade & 3 & $5(9)$ & 4 & $4(4,5)$ & 8 & $9(7)$ & 16 & $17(16)$ & 9,07 & 0,02 \\
\hline Escola & 4 & $5(9)$ & 6 & $6(7)$ & 11 & $12(10)$ & 10 & $11(11)$ & 0,91 & 0,82 \\
\hline Ganhar presentes & 8 & $9(16)$ & 8 & $9(10)$ & 9 & $10(8)$ & 5 & $6(6)$ & 5,15 & 0,16 \\
\hline Melhores finanças & 1 & $1(2)$ & 1 & $1(1)$ & 9 & $10(8)$ & 4 & $6(6)$ & 6,75 & 0,08 \\
\hline Datas festivas & 1 & $1(2)$ & 6 & $8(9)$ & 3 & $3(2)$ & 3 & $3(3)$ & 7,53 & 0,05 \\
\hline Saúde & 1 & $1(2)$ & 1 & $1(1)$ & 6 & $6(5)$ & 4 & $5(5)$ & 3,13 & 0,37 \\
\hline
\end{tabular}

Nota. $p<0,05$.

\section{Eventos de Vida Negativos}

A análise temática dos eventos de vida negativos gerou as seguintes categorias de respostas, unidas por proximidade de conteúdo e conforme sugestões da literatura:

- Morte: referências à morte de algum parente, conhecido, amigo, animal de estimação, avós. Exemplos: "morreu minha dinda" (madrinha).

- Desentendimento familiar: qualquer desentendimento (brigas, discussões), desde dis- cussões entre os pais, pais e criança, separação e divórcio dos pais, saída de um dos pais de casa. Exemplos: "minha mãe brigou com a minha tia", "meu pai xingou meu irmão", "briguei com o meu primo".

- Privação: situações de não satisfação de necessidades básicas, de desejos, de afeto, de companhia. Exemplos: "fico sozinha", "não tenho dinheiro", "quero alguma coisa que a mãe não pode dar". 
- Saúde/doença: preocupação com a saúde (psicológica ou física) própria ou de outrem, referências a doenças, acidentes, estado emocional abalado de algum parente. Exemplos: "quebrei a perna", "quebrei o braço", "a vó teve um derrame" (acidente vascular cerebral), "o pai foi para o hospital com úlcera", "eu caí".

- Desentendimentos com amigos: problemas de relacionamento com amigos e colegas, como brigas, discussões, falta de respeito, mentiras, competitividade. Exemplos: "colega me derruba", "brigas com amigas".

- Escola: dificuldades enfrentadas pelas crianças na escola, como ser maltratado na escola (pela professora ou colegas), repetir o ano escolar, tirar notas baixas, ir mal na prova, receber advertência, estudar matéria que não gosta. Exemplos: "tive que trocar de escola", "ter aula especial".

- Outras respostas: respostas que não puderam ser incluídas nas categorias descritas.

- Nada/não sabe.

As frequências e os percentuais das categorias de eventos negativos são apresentados na Tabela 4, por sexo bem como os resultados do teste binomial. Não constam na tabela os dados para as categorias nada/não sabe $(n=18 ; f=$ $18 ; 6,6 \%)$ nem outras respostas $(n=16 ; f=16$; $5,9 \%)$.

Tabela 4

Frequências, Porcentagens e Resultados do Teste Binomial para Diferenças entre Duas Proporções nos Eventos de Vida Negativos, por Sexo

\begin{tabular}{lcccccccc}
\hline & \multicolumn{2}{c}{ Total } & \multicolumn{2}{c}{ Meninas } & \multicolumn{2}{l}{ Meninos } \\
\cline { 2 - 8 } & $n$ & $f(\%)$ & $n$ & $f(\%)$ & $n$ & $f(\%)$ & $Z$ & $p$ \\
\hline Morte & 43 & $55(20)$ & 31 & $41(29)$ & 12 & $14(11)$ & 3,68 & 0,01 \\
Desentendimento familiar & 42 & $52(19)$ & 20 & $24(17)$ & 22 & $28(22)$ & $-1,0$ & 0,31 \\
Privação & 37 & $42(15,5)$ & 17 & $20(14)$ & 20 & $22(17)$ & $-0,67$ & 0,49 \\
Saúde/doença & 36 & $41(15)$ & 15 & $17(12)$ & 21 & $24(19)$ & $-1,52$ & 0,12 \\
Desentendimento c/ amigos & 32 & $38(14)$ & 14 & $19(14)$ & 18 & $19(15)$ & $-0,31$ & 0,74 \\
Escola & 8 & $9(3)$ & 5 & $6(4)$ & 3 & $3(2)$ & 0,87 & 0,38 \\
\hline
\end{tabular}

Nota. $p<0,05$

Tabela 5

Frequências, Porcentagens e Resultados do Teste Binomial para Diferenças entre Duas Proporções nos Eventos de Vida Negativos, por Tipo de Escola

\begin{tabular}{lcccccc}
\hline & \multicolumn{2}{c}{ Pública } & \multicolumn{2}{c}{ Privada } & \\
\cline { 2 - 6 } & $n$ & $f(\%)$ & $n$ & $f(\%)$ & $Z$ & $p$ \\
\hline Morte & 19 & $22(31)$ & 11 & $15(25)$ & 0,86 & 0,38 \\
Desentendimento familiar & 10 & $12(17)$ & 8 & $9(15)$ & 0,37 & 0,71 \\
Privação & 10 & $12(17)$ & 9 & $9(15)$ & 0,37 & 0,71 \\
Saúde/doença & 10 & $11(16)$ & 6 & $7(11,5)$ & 0,70 & 0,48 \\
Desentendimento amigos & 5 & $5(7)$ & 8 & $9(15)$ & $-1,40$ & 0,15 \\
Escola & 2 & $2(3)$ & 5 & $6(10)$ & $-1,66$ & 0,09 \\
\hline
\end{tabular}

Nota. $p<0,05$. 
Os testes de diferenças entre proporções apontaram diferenças significativas entre os sexos somente na categoria "morte", mais frequente para as meninas $(p=0,0002)$. A Tabela 5 mostra as frequências, porcentagens e resultados do teste binomial para diferenças entre duas proporções nos eventos de vida negativos, por tipo de escola. Não foram encontradas diferenças significativas entre os tipos de escolas, pública e privada.

A Tabela 6 apresenta as frequências, porcentagens e resultados do teste do qui-quadrado das categorias de eventos de vida negativos, por faixa etária. Foram identificadas diferenças significativas na categoria "morte", na categoria "desentendimento com amigos" e na categoria "escola". Chama a atenção a ausência de respostas das crianças de 5-6 anos quanto à morte, na comparação com as demais participantes. Sobre a escola, a tabela permite visualizar que nenhuma criança na faixa de 7-8 anos associou eventos negativos a tal contexto, ao mesmo tempo em que as de 11-12 anos trouxeram muitas respostas nessa direção. Também se percebe que os desentendimentos com as amizades foram mais citadas pelas crianças de 5-6 anos.

Tabela 6

Frequências, Porcentagens e Resultados do Teste do Qui-Quadrado das Categorias de Eventos de Vida Negativos, por Faixa Etária

\begin{tabular}{lcccccccccc}
\hline & \multicolumn{2}{c}{$5-6$ anos } & \multicolumn{2}{c}{$7-8$ anos } & $9-10$ anos & \multicolumn{2}{c}{$11-12$ anos } \\
\cline { 2 - 10 } & $n$ & $f(\%)$ & $n$ & $f(\%)$ & $n$ & $f(\%)$ & $n$ & $f(\%)$ & $X^{2}$ & $p$ \\
\hline Morte & 0 & 0 & 8 & $13(18)$ & 24 & $27(31)$ & 11 & $15(23)$ & 17,76 & 0,01 \\
Desentendimento familiar & 7 & $8(18)$ & 13 & $19(26)$ & 11 & $13(15)$ & 10 & $11(17)$ & 3,74 & 0,29 \\
Privação & 6 & $8(18)$ & 7 & $8(11)$ & 13 & $15(17)$ & 11 & $11(17)$ & 1,55 & 0,66 \\
Saúde/doença & 5 & $5(11)$ & 12 & $14(19)$ & 12 & $14(16)$ & 7 & $8(12)$ & 2,04 & 0,56 \\
Desentendimento c/ amigos & 11 & $12(27)$ & 5 & $9(12,5)$ & 8 & $8(9)$ & 8 & $9(14)$ & 8,18 & 0,04 \\
Escola & 1 & $1(2)$ & 0 & 0 & 2 & $2(2)$ & 5 & $6(9)$ & 9,68 & 0,02 \\
\hline
\end{tabular}

Nota. $p<0,05$.

Destaca-se a riqueza de dados obtidos a partir de duas questões. As categorias permitem observar os sentidos que as crianças trouxeram aos EV positivos e negativos. Já os cálculos estatísticos permitem salientar os dados mais representativos na presente amostra. Dessa forma, buscou-se contemplar tanto a abordagem qualitativa como a quantitativa, especialmente considerando-se a raridade de trabalhos que investigam EV em crianças.

Com respeito aos EV positivos, em resumo nota-se que os mais citados pelas crianças foram família, lazer, amizade, escola e ganhar presentes. As meninas citaram mais a família como EV positivo do que os meninos, enquanto estes apontaram mais as datas festivas do que as meninas. Nas diferenças etárias, uma grande frequência de respostas foi notada nas respostas das crianças de 11-12 anos na citação à amizade como EV positivo.

Os EV negativos mais mencionados foram morte, desentendimento familiar, privação, saúde/doença e desentendimento com amigos. Nas diferenças de sexo, as meninas citaram mais a morte como EV negativo do que os meninos. Nas diferenças de idade, as frequências mostraram que as crianças de 5-6 anos não relataram a morte como EV negativo, mas citaram muito os desentendimentos com amigos. Da parte das crianças mais velhas, de 11-12 anos, a escola foi mais mencionada como EV negativo.

\section{Discussão}

A investigação dos EV de uma criança também fornece indícios sobre a sua qualidade de 
vida, uma vez que eventos de vida negativos são considerados fatores de risco para o desenvolvimento (Albornoz \& Bandeira, 2010; Hutz, Koller, \& Bandeira, 1996; Kristensen et al., 2004; Poletto et al., 2009). Como o número total de eventos positivos citados pelas crianças participantes do presente estudo foi superior ao de eventos negativos, pode-se sugerir uma relativa qualidade de vida positiva destas crianças. Uma maior prevalência de eventos positivos também foi observada por Giacomoni (1998).

Os EV positivos que apresentaram maior frequência foram família, lazer, amizade, escola e ganhar presentes. Os estudos de Dell'Aglio (2000) e Giacomoni (1998), bem como de Thoilliez (2011), também encontraram eventos positivos nessas temáticas com as maiores porcentagens de respostas. Enquanto no trabalho de Giacomoni (1998) as primeiras posições foram ocupadas com família, lazer, ganhar presentes, brincar e escola, em Dell'Aglio (2000) os eventos positivos mais citados foram diversão, passeios, escola, família, amizade e ganhar/comprar coisas. O estudo de Thoilliez (2011) com as crianças espanholas listou família (cuidado e carinho), amizade (ter muitos amigos), escola (conquistas escolares), festas/ganhar presentes, tempo livre, e valores morais (ajudar, compartilhar). Dessa forma, parece que a avaliação dos EV na infância deve considerar eventos nestas categorias, podendo se apresentar de forma objetiva em novos estudos para que as crianças possam se posicionar quanto à frequência e a intensidade dos mesmos.

Dentre os EV negativos, os mais citados foram sobre morte, desentendimento familiar, privação, saúde/doença, desentendimento com amigos e escola. Estas mesmas categorias de eventos negativos também foram obtidas nos estudos de Dell'Aglio (2000) e Giacomoni (1998): saúde, desentendimento familiar, inimizade, privação, morte e problemas na escola, no primeiro estudo; e doença, morte, problemas na escola, problemas familiares, desentendimentos com pares e privação/afastamento, no segundo. Thoilliez (2011) também encontrou estes temas mencionados pelas crianças como eventos negativos. Assim, pode-se observar um padrão de EV negativos mais comuns em crianças. Em geral estão relacionados à saúde e à morte, aos desentendimentos com familiares e amigos, às dificuldades encontradas no ambiente escolar e às privações. O estudo de Compas (1987) sobre eventos estressantes, baseados nas situações que incluem mudanças de vida brusca, também corrobora esses achados.

Entre os EV infantil, a escola é apontada como geradora de eventos positivos e negativos, estressantes. Hutz et al. (1996) e Marturano (1997) discutem muito bem o papel da escola, tanto como potencializadora do risco quanto protetora e promotora de resiliência infantil. É na escola que as crianças passam grande parte do seu dia, influenciando de modo muito significativo o desenvolvimento de crianças e adolescentes. A escola pode contribuir de formas distintas nas trajetórias de desenvolvimento. Por um lado, pode prover a criança com recursos de proteção como a instrumentação cognitiva, desenvolvimento de mecanismos mediadores como promoção de autoestima, autoeficácia (sucesso escolar) e abertura de oportunidades, além de desenvolvimento de autoconceito e socialização. Por outro, pode contribuir para aumentar a vulnerabilidade frente a riscos, entre esses a experiência precoce de insucesso acadêmico interfere na formação da autoestima e autoeficácia, além da desadaptação social advinda devido à evasão (Marturano, 1997).

No presente trabalho, as crianças mais velhas da amostra, de 11-12 anos de idade, foram as que mais abordaram a escola nos eventos negativos. Embora esse resultado possa ter origem em questões desenvolvimentais (por exemplo, insucesso acadêmico em virtude da passagem cognitiva das operações concretas para as operações formais, Piaget, 1964/2011) ou mais contextuais (falta de professores, p. ex.), considera-se de fundamental importância a realização de futuros estudos sobre o papel da escola enquanto agente promotor e interventor nos níveis positivos de bem-estar subjetivo infantil.

Quanto às diferenças de sexo, o estudo de Giacomoni (1998) não encontrou eventos positivos que diferenciassem meninos e meninas apenas, mas na interação tipo de família e sexo 
da criança. O presente trabalho, por outro lado, notou que, como eventos positivos, as meninas citaram mais a família, e os meninos as datas festivas; nos negativos, as meninas referiram mais a morte do que os meninos. De fato, um estudo anterior sobre indicadores de felicidade infantil encontrou diferenças de sexo que se aproximam dos resultados encontrados no presente trabalho. Naquele estudo (Giacomoni, Souza, \& Hutz, 2016) as meninas se diferenciaram significativamente dos meninos ao citarem a família como indicador da felicidade infantil, e "brigas na família" como empecilhos à própria felicidade. Os meninos indicaram também, de modo mais significativo do que as meninas, que a felicidade na infância depende de satisfação de necessidades básicas e de lazer, e que a própria felicidade depende muito de brincar. Estes dados se assemelham à referência que os meninos fizeram às datas festivas no presente trabalho. De todo modo, a ausência de destaque, por parte dos meninos, em eventos negativos, no presente trabalho, sugere que é possível que as meninas sejam mais educadas e socializadas para atentar a ameaças a si e a outrem, numa perspectiva mais ampla de cuidado consigo e com outrem. Sobre a socialização das meninas estar voltada para tal perspectiva, há estudos que de modo recorrente encontram tal associação (Biaggio, 1999).

Não foram encontradas diferenças significativas entre as crianças de escolas públicas e privadas para os eventos positivos e negativos de suas vidas. Como a variável tipo de escola foi o aspecto da análise que mais se aproximaria do nível socioeconômico das famílias das crianças, poder-se-ia sugerir que as crianças não diferem quanto a essa questão na vivência de eventos positivos e negativos. No entanto, apenas novos estudos, que realmente mensurem a condição socioeconômica das crianças, poderão analisar diferenças quanto a eventos positivos e negativos.

Quanto às diferenças de faixa etária, os resultados encontrados sugerem que morte e amizade são conteúdos importantes nesse contexto. As crianças de 5-6 anos da amostra foram as que menos citaram a morte como evento negativo. Este resultado pode ter ocorrido em virtude do nível cognitivo destas crianças. Piaget (1964/2011) aponta que nessa faixa etária a criança tem dificuldades para lidar com conceitos como o de morte, não apenas por seu caráter abstrato, mas por aspectos que o engendram, como a não-reversibilidade, a noção de passagem do tempo, etc. A criança antes dos 7 anos de idade raciocina em termos de símbolos, especialmente pelo faz-de-conta, mas não possui maturidade cognitiva suficiente para lidar, por exemplo, com o entendimento da mortalidade. É um aspecto que certamente merece futuro estudo.

As outras duas diferenças etárias detectadas no exame das frequências envolvem as relações de amizade. As crianças mais velhas da amostra (11-12 anos de idade) foram as que mais citaram a amizade como evento positivo de suas vidas. Já as crianças pequenas, de 5-6 anos de idade, foram as que mais mencionaram os desentendimentos com amigos como eventos negativos de vida. Esses resultados vêm reforçar a importância da amizade para o desenvolvimento infantil. São, também, dois resultados inter-relacionados. $\mathrm{O}$ fato de que as crianças mais velhas relacionaram a amizade como importante para suas vidas, mas não os desentendimentos com amigos como eventos negativos, sugere que estas crianças de 11-12 anos já possuem os recursos sociocognitivos para lidar com os conflitos entre pares, podendo lançar mão de estratégias de resolução de conflitos as quais as crianças mais novas ainda não dispõem em sua total maturidade. Dessa forma, é possível que as crianças de 5-6 anos, por terem um pouco mais de dificuldades para lidar com os conflitos com os amigos, necessitando muitas vezes da mediação de um adulto, acabaram por referir as brigas com amigos dentre os eventos de vida negativos, do que fazer ou ter amigos como evento positivo. Com o avanço cognitivo é que essas crianças pequenas perceberão melhor as estratégias que estão envolvidas na manutenção das amizades, bem como os recursos necessários para se fazer amigos. Portanto, é provável que seja por isso que a presença das amizades seja mais valorizada pelas crianças mais velhas como evento positivo. De fato, as pesquisas mostram o impacto dos 
relacionamentos de amizade no bem-estar subjetivo e na satisfação de vida das pessoas (Argyle, 1999). Ademais, tanto o trabalho de Dell'Aglio (2000) como o de Giacomoni (1998) encontraram, nas falas das crianças participantes, que a amizade está relacionada a eventos positivos da vida infantil.

\section{Considerações Finais}

Este estudo buscou conhecer os eventos de vida positivos e negativos em crianças de 5 a 12 anos, estudantes de escolas públicas e privadas de Porto Alegre. Identificar estes eventos contribui para os esforços científicos brasileiros que vem sendo empreendidos na direção de avaliar o bem-estar subjetivo e a satisfação de vida infantil (Giacomoni \& Hutz, 2008; Giacomoni, Souza, \& Hutz, 2014a, 2014b, 2016).

Além das contribuições científicas, há implicações relevantes para os contextos escolar e clínico dedicados à infância. O psicólogo clínico infantil, ao inquirir diretamente sobre EV positivos e negativos poderá identificar em quais domínios se localizam, no momento da busca pela psicoterapia, as fontes de insatisfação e infelicidade da criança. A percepção subjetiva dos EV de uma criança vem a complementar os relatos dos pais na busca por psicoterapia para o(a) filho(a). Diante dos resultados já disponíveis em pesquisa no Brasil sobre bem-estar na criança (ver Giacomoni \& Hutz, 2006, 2008), o psicoterapeuta tem o dever de avançar para além da visão adultocêntrica dos pais e educadores da criança que vem a tratamento.

Já com respeito aos educadores, a estes importam uma comunicação eficaz com o psicoterapeuta de seu aluno, visto que suas impressões sobre domínios importantes do bem-estar infantil - como o domínio escolar e da amizade, por exemplo - complementam a avaliação do bem-estar e da satisfação de vida da criança. Ademais, a atualidade dos conhecimentos científicos do educador permitirá que ele trabalhe, na escola, temas como amizade, tempo livre e lazer, família, desempenho escolar e seus desafios, doenças e morte, festividades e seu significado, bem como privações e obrigações morais.
Além disso, o psicólogo escolar pode abordar, tanto em crianças como em adolescentes escolares, as questões de bem-estar subjetivo, por exemplo, pela via dos EV positivos e negativos. Seria uma maneira de oportunizar que os alunos tratem de aspectos de suas vidas e, ao mesmo tempo, os comparem com os colegas, com a mediação do psicólogo, e construam, juntos, formas de lidar com EV negativos e de como serem gratos aos positivos, atentando para como reproduzi-los para si e para outrem. Como mencionado na introdução, a escola compõe grande parte da vida cotidiana de crianças e, portanto, o psicólogo escolar deve tratar dos aspectos que fomentam bem-estar subjetivo nos estudantes no contexto escolar.

Com respeito a limitações do presente estudo, a amostra é restrita a crianças de uma capital do sul do Brasil, e em número reduzido por faixa etária. Ainda assim, e com base nos cálculos estatísticos apropriados para a amostra, os resultados foram semelhantes ao que a literatura vinha apontando, com pequenas diferenças, como se pode notar. Além disso, o extenso trabalho de Thoilliez (2011) com mais de 800 crianças apresentou resultados muito semelhantes, e com participantes de outro país (Espanha). Isso vem a validar os achados do presente trabalho. Ademais, quanto a futuros estudos, há que se considerar a necessidade por mais estudos sobre eventos de vida positivos e negativos em crianças brasileiras de outros estados, visto que os dados encontrados são semelhantes aos de outro país, bem como similares a estudos brasileiros prévios.

\section{Referências}

Albornoz, A. C. G., \& Bandeira, D. R. (2010). Eventos de vida: Investigações sobre a violência sexual contra crianças e adolescentes. Revista Interamericana de Psicologia, 44(3), 489-497. Recuperado em http://www.redalyc.org/articulo.oa? id=28420658011

Argyle, M. (1999). Causes and correlates of happiness. In D. Kahneman, E. Diener, \& N. Schwarz (Eds.), Well-being: The foundations of hedonic psychology (pp. 354-373). New York: Russell Sage Foundation. 
Ayres, M., Ayres, M., Jr., Ayres, D., \& Santos, A. (2000). BioEstat 2.0: Aplicações estatísticas nas áreas das ciências biológicas e médicas. Belém, PA: Sociedade Civil Mamirauá.

Bardin, L. (2011). Análise de conteúdo (ed. revista e ampliada). Lisboa: Edições 70.

Biaggio, A. M. B. (1999). Universalismo versus relativismo no julgamento moral. Psicologia: Reflexão e Crítica, 12(1), 5-20. doi:10.1590/S010279721999000100002

Compas, B. E. (1987). Stress and life events during childhood and adolescence. Clinical Psychology Review, 7, 275-302. doi:10.1016/02727358(87)90037-7

Dell'Aglio, D. D. (2000). O processo de coping, institucionalização e eventos de vida em crianças e adolescentes (Tese de doutorado, Universidade Federal do Rio Grande do Sul, Porto Alegre, RS, Brasil). Recuperado em http://www.lume.ufrgs. br/handle/10183/2909

Diener, E., Lucas, R., Oishi, S., \& Suh, E. (2002). Looking up and down: Weighting good and bad information in life satisfaction judgments. Personality and Social Psychology Bulletin, 28(4), 437-445. doi:10.1177/0146167202287002

Giacomoni, C. H. (1998). Desempenho acadêmico, controle percebido e eventos de vida como preditores de bem-estar subjetivo em crianças (Dissertação de mestrado, Programa de Pós-Graduação em Psicologia, Universidade Federal do Rio Grande do Sul, Porto Alegre, RS, Brasil).

Giacomoni, C. H., \& Hutz, C. S. (2006). Escala de afeto positivo e negativo para crianças: Estudos de construção e validação. Psicologia Escolar e Educacional, 10(2), 235-245. doi:10.1590/ S1413-85572006000200007

Giacomoni, C. H., \& Hutz, C. S. (2008). Escala multidimensional de satisfação de vida para crianças: Estudos de construção e validação. Estudos de Psicologia (Campinas), 25(1), 23-35. doi:10.1590/S0103-166X2008000100003

Giacomoni, C. H., Souza, L. K. de, \& Hutz, C. S. (2014a). O conceito de felicidade em crianças. Psico-USF, 19(1), 143-153. doi:10.1590/S141382712014000100014

Giacomoni, C. H., Souza, L. K. de, \& Hutz, C. S. (2014b). A visão das crianças sobre a felicidade. Psicologia Escolar e Educacional, 18(1), 143150. doi:10.1590/S1413-85572014000100015
Giacomoni, C. H., Souza, L. K. de, \& Hutz, C. S. (2016). Indicadores de bem-estar subjetivo infantil: o que dizem as crianças. In C. S. Hutz (Ed.), Avaliação em Psicologia Positiva: Técnicas e medidas (pp. 103-123). São Paulo, SP: Hogrefe CETEPP.

Hinkle, P. E., Wiersma, W., \& Jurs, S. G. (1988). Applied statistics for the behavioral sciences. Boston, MA: Hougthon Miffin.

Hutz, C. S., Koller, S. H., \& Bandeira, D. R. (1996). Resiliência e vulnerabilidade em crianças em situação de risco. In S. H. Koller (Ed.), Aplicações da psicologia na melhoria da qualidade de vida (pp. 79-86). Porto Alegre, RS: Associação Nacional de Pesquisa e Pós-graduação em Psicologia.

King, K., Molina, B., \& Chassin, L. (2008). A state-trait model of negative life event occurrence in adolescence: Predictors of stability in the occurrence. Journal of Clinical Child \& Adolescent Psychology, 37(4), 848-859. doi:10.1080/15374410802359643

Kristensen, C., Leon, J., D’Incao, D., \& Dell'Aglio, D. (2004). Análise da frequência e do impacto de eventos estressores em uma amostra de adolescentes. Interação em Psicologia, 8(1), 45-55. doi:10.5380/psi.v8i1.3238

Larson, R. (1990). The solitary side of life: An examination of the time people expend alone from childhood to old age. Developmental Review, 10, 155-83. doi:10.1016/0273-2297(90)90008-R

Marturano, E. M. (1997). A criança, o insucesso escolar precoce e a família: Condições de resiliência e vulnerabilidade. In E. M. Marturano, S. R. Loureiro, \& A. W. Zuardi (Eds.), Estudos em saúde mental (pp. 130-149). Ribeirão Preto, SP: Comissão de Pós-Graduação em Saúde Mental, Universidade de São Paulo.

Maybery, D., Jones-Ellis, J., Neale, J., \& Arentz, A. (2006). The Positive Event Scale: Measuring uplift frequency and intensity in an adult sample. Social Indicators Research, 78, 61-83. doi:10.1007/s11205-005-4096-8

Oliveira, M., Fonseca, P., \& Del Porto, J. (2002). Versão brasileira da entrevista de Paykel para eventos de vida recentes. Revista Brasileira de Terapia Comportamental e Cognitiva, 4(1), 47-61. Recuperado em http:// pepsic.bvsalud.org/scielo.php?pid=S1517$-55452002000100006 \&$ script=sci_arttext 
Piaget, J. (2011). Seis estudos de psicologia. Rio de Janeiro, RJ: Forense Universitária. (Original publicado em 1964)

Poletto, M., Koller, S. H., \& Dell'Aglio, D. D. (2009). Eventos estressores em crianças e adolescentes em situação de vulnerabilidade social de Porto Alegre. Ciência \& Saúde Coletiva, 14(2), 455466. doi:10.1590/S1413-81232009000200014

Suh, E., Diener, E., \& Fujita, F. (1996). Events and subjective well-being: Only recent events matter. Journal of Personality and Social Psychology, 70, 1091-1102. doi:10.1037/00223514.70.5.1091

Thoilliez, B. (2011). How to grow up happy: An exploratory study on the meaning of happiness from children's voices. Child Indicators Research, 4, 323-351. doi:10.1007/s12187-011-9107-5

Woyciekoski, C., Natividade, J., \& Hutz, C. S. (2014). Eventos de vida constituem um construto? Evidências da impossibilidade de considerar eventos de vida um construto. Temas em Psicologia, 22(1), 13-24. doi:10.9788/TP2014.1-02
Woyciekoski, C., Stenert, F., \& Hutz, C. S. (2012). Determinantes do bem-estar subjetivo. Psico, 43(3), 280-288. Recuperado em http://revistaseletronicas.pucrs.br/ojs/index.php/revistapsico/ article/view/8263/8228

Zeidner, M., \& Endler, N. S. (1996). Handbook of coping. New York: Wiley.
Recebido: 03/11/2014

$1^{a}$ revisão: $21 / 08 / 2015$

$2^{a}$ revisão: $22 / 10 / 2015$

$3^{a}$ revisão: $14 / 11 / 2015$

Aceite final: 08/12/2015 